\title{
Action of fenoxycarb on metamorphosis and cocoon spinning in Chrysoperla carnea (Neuroptera: Chrysopidae): identification of the JHA-sensitive period
}

\author{
LAURA BORTOLOTTI, ANNA MICCIARELLI SBRENNA and GIOVANNI SBRENNA
}

Dipartimento di Biologia, Università di Ferrara, Via Borsari 46, 44100 Ferrara, Italy; e-mail: sbr@unife.it

Key words. Chrysoperla carnea, juvenoids, fenoxycarb, development, metamorphosis, JH sensitive period

\begin{abstract}
Fenoxycarb is an insecticide with a juvenile hormone mimicking effect, which disturbs metamorphosis in several insect species, including the neuropteran Chrysoperla carnea. Administration of different doses of fenoxycarb to third instar larvae causes a dose dependent inhibition of metamorphosis and cocoon spinning. When treated within $48 \mathrm{~h}$ of the last larval ecdysis, this insect shows a temporary inhibition of metamorphosis and cocoon spinning, which leads to a prolongation of the third larval instar. When treated after $60 \mathrm{~h}$ into the last instar, most of larvae were unable to metamorphose and spin a cocoon. Thus, C. carnea is most sensitive to this juvenoid in the period after $60 \mathrm{~h}$ into the last larval instar.
\end{abstract}

\section{INTRODUCTION}

Several studies on a large range of species demonstrate that Juvenile Hormone ( $\mathrm{JH})$ or Juvenile Hormone Analogues (JHA) only have an effect when administrated at a particular time during larval development. Generally, in Lepidoptera the most sensitive period for the induction of morphological effects by JHA is the last larval instar, in particular the third quarter of this instar (Sehnal, 1983). This "temporal window", during which cells are responsive to the hormone, is called "JHA-sensitive period".

Chrysoperla carnea Steph. is a Neuropteran that has three larval instars, at the end of which the larva spins a silk cocoon using material from its Malpighian tubules. The third instar larva enclosed in the cocoon (prepupa) transforms into a decticous pupa. A pharate adult leaves the cocoon a few hours before the imaginal ecdysis (Canard et al., 1984). Very little is known about the hormonal regulation of metamorphosis in Neuroptera and the fluctuation in $\mathrm{JH}$ during larval development has never been investigated.

Fenoxycarb, a non-neurotoxic carbamate insecticide, is classified as an insect grow regulator because of its juvenile hormone-mimicking effect. In many insects it interferes with development by inhibiting or disturbing metamorphosis, leading to supernumerary larval instars, permanent larvae, larva/adult, larva/pupa or pupa/adult intermediates (Grenier \& Grenier, 1993). In the silkworm Bombyx mori L., presence of even low concentrations of fenoxycarb inhibits cocoon spinning (Plantevin et al., 1991; Cappellozza et al., 1995; Kamimura, 1995). Because of the great economic losses caused by fenoxycarb in sericulture, and its side effects on honeybees and beneficial insects, its use was banned in Italy and limited in other countries. Fenoxycarb also provokes alterations in larval development and inhibits metamorphosis and cocoon spinning in C. carnea (Triebskorn et al., 1991; Vogt, 1992; Rumpf \& Penman, 1993; Bigler \& Waldburger, 1994; Bortolotti et al., 2000).
The exact mode of action of fenoxycarb is still unknown. In the Lepidopteran Manduca sexta, application of fenoxycarb causes a decrease in $\mathrm{JH}$ levels in fourth instar larvae, but the symptoms shown by the treated insects are those of an excess of JH (Baker et al., 1986). This suggests a negative feedback system in which the administration of fenoxycarb suppresses JH biosynthesis by the corpora allata, and that the exogenous molecule takes over the role of the endogenous JH.

The aim of this work is to describe the action of fenoxycarb on $C$. carnea and define the JHA-sensitive period in the last larval instar.

\section{MATERIAL AND METHODS}

\section{Experimental animals}

Eggs and first instar larvae of $C$. carnea were obtained from the biofarm Biolab (now Bioplanet), Cesena, Italy. Larvae were kept in transparent cylindrical plastic boxes $(4 \mathrm{~cm} \times 3.5 \mathrm{~cm})$ and fed daily with eggs of Ephestia kuehniella. Each larva was kept individually in a box to avoid cannibalism, very common in the larvae of this species. The boxes were placed in a climate chamber at $24^{\circ} \mathrm{C}\left( \pm 3^{\circ} \mathrm{C}\right)$ with a constant photoperiod of $16 \mathrm{~h}$ light and $8 \mathrm{~h}$ darkness.

The times of the first and second larval ecdyses were recorded and the duration of the larval stages calculated. The larvae were treated during the third, i.e. last larval instar, as described in the next paragraph. After treatment the larvae were kept in the same conditions as before. Their development was followed until adult emergence or death.

\section{Application of fenoxycarb}

Fenoxycarb was topically administered $(1 \mathrm{ml}$ on the dorsal part of the abdomen) to the third instar larvae in four different "hour-groups", classified according to the hours that had elapsed since the last larval ecdysis: $24 \mathrm{~h}, 48 \mathrm{~h}, 60 \mathrm{~h}$ and $72 \mathrm{~h}$. Three doses of the formulated product Insegar ${ }^{\circledR}(25 \%$ fenoxycarb) diluted in water, were used $(0.0014 \mu \mathrm{g}$ a.i./larva, $0.07 \mu \mathrm{g}$ a.i./larva and $0.14 \mu \mathrm{g}$ a.i./larva) and one dose of the nonformulated fenoxycarb diluted in acetone $(0.75 \mu \mathrm{g} /$ larva $) .132$ larvae were treated with each dose, namely 33 for each hourgroup. 
Three replicates of 33 larvae were treated with water (water control), three replicates of 33 larvae with acetone (acetone control) and both groups were kept in a climate chamber located in another building, to avoid drift phenomena; three replicates of 33 untreated larvae were kept in the same climate chamber with the treated larvae, to control for the effect of drift (drift control). Control larvae were treated between 48 and $60 \mathrm{~h}$ into the last larval instar.

Differences in the duration of the developmental periods among the three kinds of controls and the treated larvae were analysed using the Mann-Whitney U-test. Difference in the effects of the four doses on the four hour-groups were analysed using the $\chi^{2}$ test.

The fine structure of the cocoons spun by the untreated and treated larvae was studied using a scanning electron microscope (SEM). The cocoons were coated with a gold-platinum layer in an Edwards vacuum chamber and examined using a Siemens Autoscan SEM.

\section{RESULTS}

\section{Development of untreated larvae}

From the data for the three groups of untreated larvae (water control, acetone control and drift control) the mean duration of the developmental stages in our experimental conditions were calculated and compared with those reported by other authors (Table 1).

Since some larvae were already in the first larval instar at the beginning of the experiment, the preimaginal development was described starting from the first larval ecdysis. For the water control, the duration of the second larval instar varied from 1 to 4 days (mean 2.23 days); the third instar larva 3 to 5 days (mean 3.50 days) as free living larva before starting to spin a cocoon; cocoon spinning lasted only few hours and the duration of the prepupal + pupal periods varied from 10 to 13 days (mean value 10.77 days). These results conform with those found for the same species by other authors (Canard et al., 1984). The prepupal period of $C$. carnea, which was not measured in our study, occurs within the cocoon and lasts about 3.8-4.8 days, according to other authors (Canard et al., 1984).

No significant differences were found in the developmental time and in percentage of larvae with inhibition of metamorphosis and cocoon spinning between larvae in the water and acetone controls. Although the larvae in the drift control showed a higher percentage of inhibition of metamorphosis than those in the other two groups, these differences are not statistically significant.

\section{Development of treated larvae}

Larvae treated with fenoxycarb showed two major alterations of preimaginal development: i) the inhibition of metamorphosis and ii) the inhibition of cocoon spinning.

i) Metamorphosis was strongly affected by fenoxycarb. Aside from the presence or not of a complete cocoon, a high percentage of larvae did not succeed in metamorphosing to adults. Insects were considered to be affected by inhibition of metamorphosis when: a) they were still alive when the non-affected larvae were already inside a cocoon and $b$ ) they continued as larvae, prepupae, pupae or pharate adults, never becoming adults. When mortality occurred in the period when the non-affected larvae had already metamorphosed, this was considered to be a consequence of metamorphosis inhibition, although the exact cause of mortality was unknown.

The duration of the third larval instar of affected larvae was calculated from the last larval ecdysis to the pupal ecdysis (if it occurred) or to death. We identified 4 kinds of metamorphosis inhibition, according to the developmental stage achieved by the treated larvae.

The first group of larvae remained permanently as larvae and did not spin a cocoon. These "permanent larvae" prolonged their larval period by about 5 times (up to 56 days maximum) and attained a much greater size than normal third instar larvae. In the last part of their larval life they became sluggish, ceased feeding and often assumed a green colour.

The second group failed to metamorphose: they started but did not complete cocoon spinning. They showed the characteristic appearance of prepupae: the thorax was broadened and flattened, the integument shiny and transparent. These larvae often adopted a C-shaped position, typical of prepupa inside a cocoon, even although the cocoon was incomplete.

The third group reached the pupal stage but often performed an incomplete ecdysis and died with the larval exuviae wrapped around the abdomen of the pupa. Sometimes the head and thorax had adult pigmentation and the abdomen larval features.

The fourth group developed to the pharate adult stage, both in the presence or absence of a cocoon, but died before adult emergence.

ii) The inhibition of cocoon spinning can be total, when the larvae are unable to secrete the silken threads, or partial, when the larvae can secrete silk, but the resulting cocoon is incomplete or irregular. We call a cocoon "incomplete" when it was formed of only a few silk threads or did not completely cover a larva; a cocoon is "irregular" when it enclosed a larva, but its "architecture" was aberrant.

TABLE 1. Duration of preimaginal development (mean \pm st. dev.), and percentage of the control larvae of C. carnea reared under laboratory conditions that showed inhibition of metamorphosis and cocoon spinning.

\begin{tabular}{lccccc}
\hline Controls & $\begin{array}{c}\text { II larval instar } \\
\text { (days) }\end{array}$ & $\begin{array}{c}\text { III larval instar } \\
\text { (free living) (days) }\end{array}$ & $\begin{array}{c}\text { Prepupa + pupa } \\
\text { (inside the cocoon) (days) }\end{array}$ & $\begin{array}{c}\text { Inhibition of } \\
\text { metamorphosis (\%) }\end{array}$ & $\begin{array}{c}\text { Inhibition of cocoon } \\
\text { spinning (\%) }\end{array}$ \\
\hline Water control & $2.23 \pm 0.62$ & $3.50 \pm 0.68$ & $10.77 \pm 0.69$ & 8.00 & 0.00 \\
Acetone control & $2.32 \pm 0.55$ & $3.12 \pm 0.68$ & $11.25 \pm 0.79$ & 8.00 & 4.00 \\
Drift control & $2.55 \pm 0.77$ & $3.72 \pm 0.46$ & $11.89 \pm 0.99$ & 21.74 & 4.35 \\
\hline
\end{tabular}



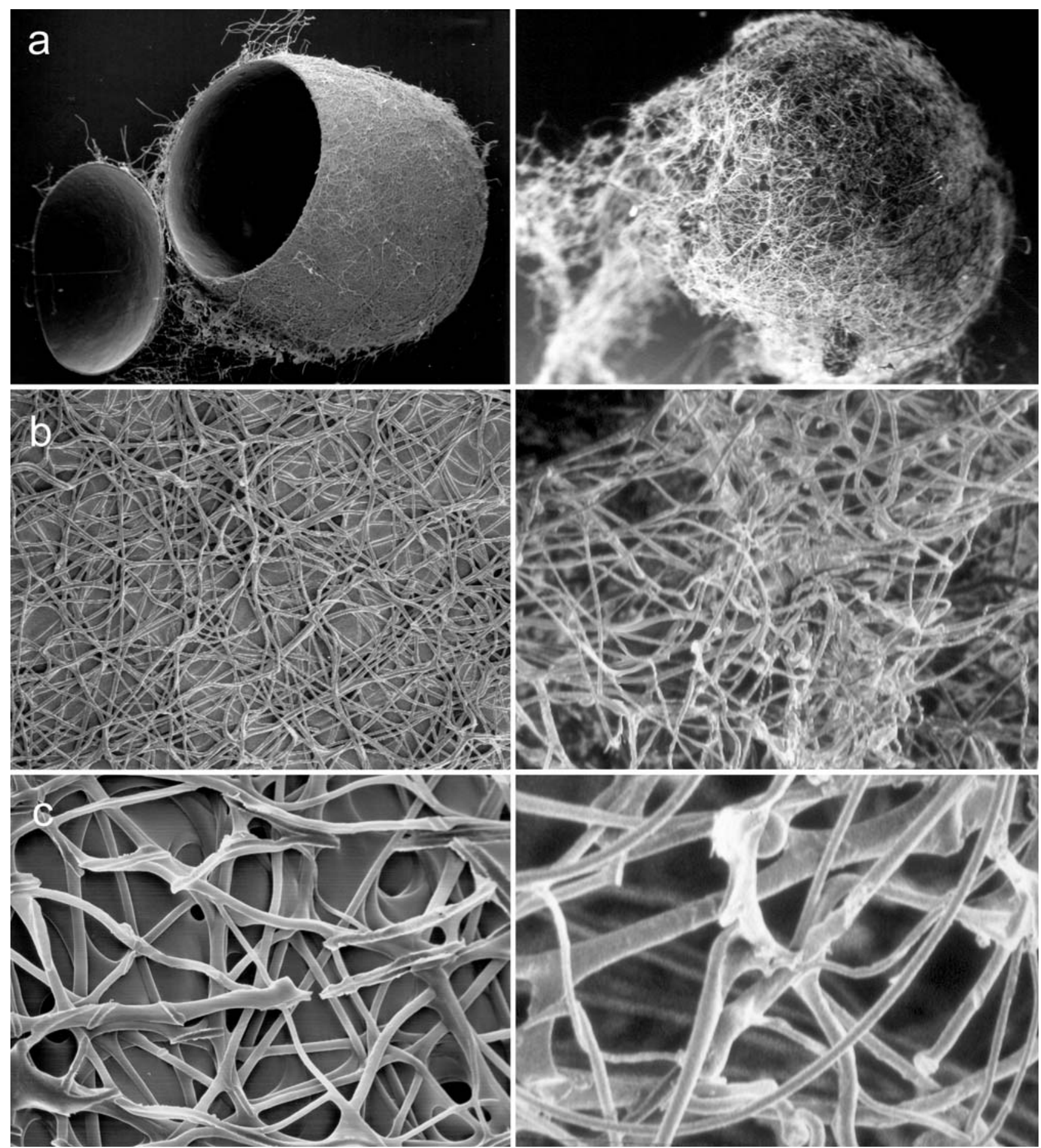

Fig. 1. Scanning electron micrographs of the fine structure of the cocoon of an untreated (left) and treated larva (right); magnification scale: $1 \mathrm{a}-15 \times ; 1 \mathrm{~b}-300 \times ; 1 \mathrm{c}-600 \times$.

The difference between a regular and an irregular cocoon is fully evident in Fig. 1, which shows outside views of the two kinds of cocoon. The structure of the regular cocoon (Fig. 1, left) reveals two different layers: the outer layer is composed of a thick distinct mesh, orderly disposed, and the inner of threads that blend and fuse together, to form a compact and smooth surface (greyish mass in the background of pictures $1 \mathrm{a}$ and $1 \mathrm{~b}$ ). In contrast, the outer layer of an irregular cocoon (Fig. 1, right) is composed of chaotically arranged threads and the inner layer is thin or absent.

\section{Action of fenoxycarb on third instar larvae of different ages}

The mean duration of development of the treated third instar larvae is summarised in Table 2. For all the doses and hour-groups, the treatment caused a significant prolongation of the third larval instar $(\mathrm{p}<0.00)$ compared to the control. This effect is much more evident in larvae 
TABLE 2. Mean duration of the third larval instar of the four hour-groups of larvae treated with different doses of fenoxycarb. Mean \pm standard deviation; between brackets the range of values.

\begin{tabular}{ccccc}
\hline \multicolumn{5}{c}{ Duration of III larval instar (days) } \\
\hline \multirow{5}{*}{ Dose $(\mu$ g a.i./larva) } & 24 & 48 & 60 & 72 \\
\cline { 2 - 5 } & $4.64 \pm 0.50$ & $4.56 \pm 0.53$ & $4.22 \pm 0.55$ & $4.29 \pm 0.96$ \\
0.0014 & $(4-5)$ & $(4-5)$ & $(4-6)$ & $(4-8)$ \\
& $4.70 \pm 0.98$ & $5.48 \pm 1.52$ & $5.33 \pm 0.96$ & $4.91 \pm 2.44$ \\
0.07 & $(4-8)$ & $(4-11)$ & $(4-9)$ & $(3-15)$ \\
& $7.09 \pm 3.92$ & $7.03 \pm 4.31$ & $19.85 \pm 12.20$ & $20.36 \pm 12.81$ \\
0.14 & $(4-18)$ & $(4-23)$ & $(4-49)$ & $(6-49)$ \\
& $22.31 \pm 10.98$ & $32.08 \pm 14.02$ & $26.65 \pm 8.33$ & $25.33 \pm 12.63$ \\
& $(9-49)$ & $(12-56)$ & $(11-44)$ & $(4-48)$ \\
\hline
\end{tabular}

treated at 60 and $72 \mathrm{~h}$ with a dose of $0.14 \mu \mathrm{g} / \mathrm{larva}$, and for all larvae treated with $0.75 \mu \mathrm{g} /$ larva.

i) The action of fenoxycarb on the metamorphosis of third instar larvae treated at different ages is presented in Fig. 2. At the two lower doses (0.0014 and 0.07 $\mu \mathrm{g} /$ larva), for all hour-groups, there are no significant differences in the inhibition of metamorphosis, compared to the control. Most of the larvae that showed a disruption of metamorphosis died as pupae, fewer as prepupae or pharate adults and those given a dose of $0.07 \mu \mathrm{g}$ remained permanently as larvae.

Larvae treated with $0.14 \mu \mathrm{g}$ at 48,60 and $72 \mathrm{~h}$ showed significant difference compared to the controls $(p=0.04$, $\mathrm{p}<0.00$ and $\mathrm{p}<0.00$ respectively). When the dose was the same, the difference between those treated before $48 \mathrm{~h}$ and after $60 \mathrm{~h}$ is significant $(\mathrm{p}<0.00)$, with the latter resulting in a higher percentage of metamorphosis inhibition, near to $100 \%$. In the 24 and 48 hour-groups mostly pharate adults, prepupae and fewer pupae developed, and the percentage of permanent larvae increased progressively with the hour of treatment, from about $5 \%$ in the 24 to almost $40 \%$ in the 72 hour-group.

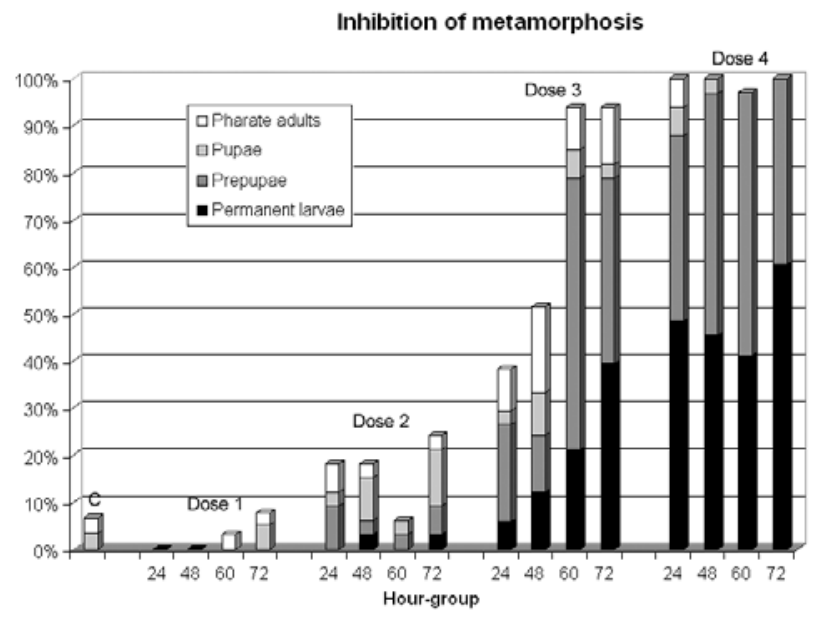

Fig. 2. Inhibition of metamorphosis caused by the four doses of fenoxycarb applied to the four hour-groups of larvae $(\mathrm{C}=$ control; Dose $1=0.0014 \mu \mathrm{g}$ a.i./larva; Dose $2=0.07 \mu \mathrm{g}$ a.i./larva; Dose $3=0.14 \mu \mathrm{g}$ a.i./larva; Dose $4=0.75 \mathrm{~g}$ a.i./larva). Histograms show the 4 kinds of metamorphosis inhibition referred to in the text.
At a dose $0.75 \mu \mathrm{g} /$ larva nearly all the larvae showed disrupted metamorphosis in all the hour-groups and are significantly different from the control $(\mathrm{p}<0.00)$. Conversely, there are no significant differences among the four hour-groups. Most of the larvae died as permanent larvae or prepupae in all the four hour-groups; few pupae and pharate adults were present in the 24 hour-group and only few pupae in the 48 hour-group.

ii) The action of fenoxycarb on cocoon spinning by third instar larvae of different ages is presented in Fig. 3. The lower dose $(0.0014 \mu \mathrm{g} /$ larva $)$ did not influence cocoon spinning; only at $72 \mathrm{~h}$ there was a small but insignificant inhibition of cocoon spinning. At a dose 0.07 $\mu \mathrm{g} /$ larva the inhibition is significantly different from the control only in the 72 hour-group $(p=0.02)$. Most of the larvae of this group produced an irregular cocoon.

When treated with a dose of $0.14 \mu \mathrm{g} /$ larva, the hourgroups 48, 60 and 72 showed significant inhibition of cocoon spinning $(\mathrm{p}=0.02, \mathrm{p}<0.00, \mathrm{p}<0.00)$ and a significant difference between the treatments before 48 and after $60 \mathrm{~h}(\mathrm{p}<0.00)$. For all hour-groups most of the larvae showed complete cocoon spinning inhibition.

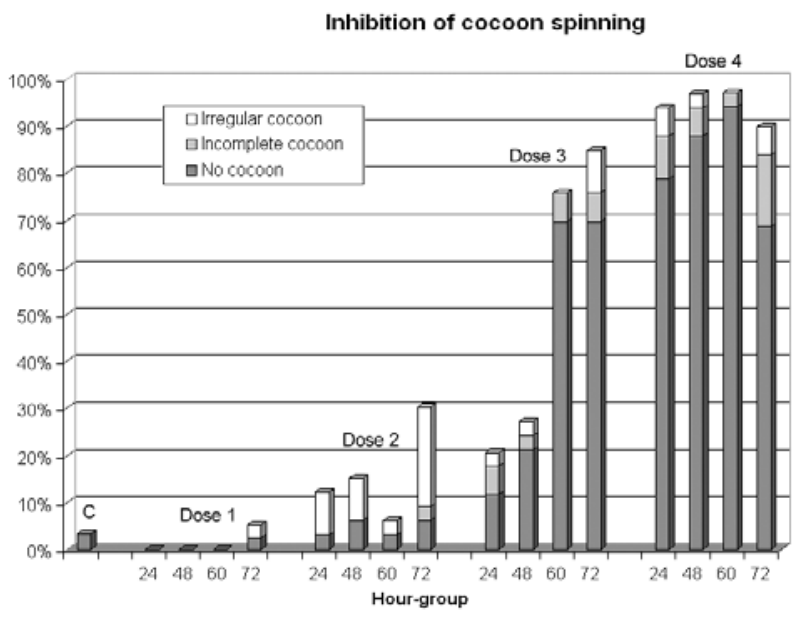

Fig. 3. Inhibition of cocoon spinning caused by the four doses of fenoxycarb applied to the four hour-groups $(\mathrm{C}=$ control; Dose $1=0.0014 \mu \mathrm{g}$ a.i./larva; Dose $2=0.07 \mu \mathrm{g}$ a.i./larva; Dose $3=0.14 \mu \mathrm{g}$ a.i./larva; Dose $4=0.75 \mathrm{~g}$ a.i./larva). Histograms show the 3 kinds of cocoon spinning inhibition referred to in the text. 
When treated with a high dose $(0.75 \mu \mathrm{g} /$ larva $)$, the difference between treated and control larvae in cocoon spinning inhibition are always significant $(p<0.00)$, whereas there are no significant differences among the four hour-groups. Most of the larvae treated with this dose showed inhibition of cocoon spinning.

\section{CONCLUSIONS AND DISCUSSION}

The effects of fenoxycarb on $C$. carnea observed in our experiment conform with those previously reported in which other JHA were used on the same insect (Bull et al., 1973; Růžička et al., 1978; Romanchenko et al., 1987; Triebskorn et al., 1991; Rumpf et al., 1992; Vogt, 1994). This supports the hypothesis that fenoxycarb acts as a JHA on the physiology of $C$. carnea.

The hormonal regulation of metamorphosis in Lepidoptera is described for many species (Tanaka et al., 1989; Jones et al., 1990; Niimi \& Sakurai, 1997). In all these Lepidoptera, the $\mathrm{JH}$ level is low during the last larval instar and declines prior to cocoon spinning. During this period larvae are highly sensitive to JHA (Sehnal, 1983).

If we hypothesize that hormonal regulation in $C$. carnea is similar to that in Lepidoptera, the larvae treated at the beginning of the third larval instar should be less sensitive to fenoxycarb than those treated at the end of the instar. Our results confirm this prediction: the development of larvae treated in the second half of the third instar was more affected than that of larvae treated within $48 \mathrm{~h}$ of ecdysis. In particular, the period between 48 and $60 \mathrm{~h}$ after the ecdysis marks the beginning of the fenoxycarbsensitive period, that continues until the start of cocoon spinning. The treatment of the 48 hour-group with 0.14 $\mu \mathrm{g} /$ larva produced about $52 \%$ metamorphosis inhibition and $27 \%$ cocoon spinning inhibition, and these percentages increased to about $94 \%$ and $76 \%$ for the 60 hourgroup and $94 \%$ and $85 \%$ for the 72 hour-group. Our results agree with those of Růžička et al. (1978), which show that the sensitive period to juvenoids in $C$. carnea starts in the last larval instar and extends over the whole prepupal period.

In our experiment both the dose and the period of application influence the specific effect of fenoxycarb. Low doses provoked a reversible delay in metamorphosis, which did not completely prevent further development. A high dose caused a longer developmental delay and irreversible effects in almost $100 \%$ of the larvae; about half of them showed complete inhibition of metamorphosis and the development of permanent larvae.

The reversible effects observed with low doses could be due to an inhibition of the secretion of ecdysone (Dedos et al., 1998; Dedos \& Fugo, 1999); this causes a delay in the larva-pupa moult and a prolongation of the larval period. When the fenoxycarb is metabolised, the development of $C$. carnea can proceed without permanent damage to the insect. Similarly, when treated during the first part of the third larval instar (within $48 \mathrm{~h}$ of the last larval ecdysis) a high percentage of larvae were able to metabolise the fenoxycarb and only showed a delay in metamorphosis. In contrast, when treated towards the end of the third larval instar (after $60 \mathrm{~h}$ after the last larval ecdysis) the larvae are unable to metabolise the fenoxycarb and most died without metamorphosing.

It is also possible to distinguish a dependence on the timing of the treatment, when an intermediate dose $(0.14$ $\mu \mathrm{g} /$ larva) was used: when applied before $48 \mathrm{~h}$, the effect is transitory for more than half of the larvae and the percentage of permanent larvae was about $10 \%$; when applied after $60 \mathrm{~h}$, a block on metamorphosis affected almost all the larvae, and the percentage of permanent larvae varied from $20 \%$ to $40 \%$.

The explanation is that the JH-sensitive period is in the final part of the third instar, and at this time the presence of JH, or a JHA like fenoxycarb, causes an irreversible retention of larval characteristics.

Since different tissues have a different threshold of sensitivity to the $\mathrm{JH}$ and not all the tissues reach the pupal characteristics at the same time (Nijhout, 1994), treatment with JHA can cause the development of larva-pupa or larva-adult intermediate individuals. In this study, we recorded larvae that incompletely switched to pupae or adults, but died as pupae, whose abdomen had larval characteristics, or as permanent larvae, prepupae or pupae, with the green pigmentation typical of adults. Similar responses are observed in other insects, for example B. mori (Cappellozza et al., 1995).

The influence of fenoxycarb on cocoon spinning, well documented in the silkworm B. mori (Plantevin et al., 1991; Cappellozza et al., 1995; Kamimura, 1995), occurred in C. carnea. The inhibition of cocoon spinning was similar to the effect on metamorphosis: a low dose of fenoxycarb provoked a partial inhibition, with the production of irregular or incomplete cocoons (larvae did not produce the inner layer), while a higher dose prevented silk secretion. Moreover, cocoon spinning was qualitatively more affected by fenoxycarb than metamorphosis, with almost total inhibition at the two highest doses. This did not happen in metamorphosis, where some of the larvae developed to the prepupal and pupal stages, even in the absence of a cocoon.

Another difference from metamorphosis inhibition is that cocoon spinning is always totally inhibited by an intermediate dose $(0.14 \mu \mathrm{g} / \mathrm{larva})$, whenever fenoxycarb was applied. Probably this is because metamorphosis is a complicated process, that involves several events whose control is not simultaneous. In contrast, cocoon spinning is a relatively simple process, possibly controlled by a "single switch".

In conclusion, third instar larvae treated with fenoxycarb at different ages revealed previously unknown aspects of hormonal regulation of metamorphosis in $C$. carnea. Our results indicate that the onset of metamorphosis occurs after $60 \mathrm{~h}$ into the last larval instar and is sensitive to fenoxycarb, and this probably corresponds to the JHA-sensitive period described in other insects.

\section{REFERENCES}

Baker F.C., Miller C.A., Tsai L.W., Jamieson G.C., Cerf D.C. \& Schooley D.A. 1986: The effect of juvenoids, anti juvenile hormone agents, and several intermediates of juvenile hor- 
mone biosynthesis on the in vivo juvenile hormone levels in Manduca sexta larvae. Insect Biochem. 16: 741-747.

Bigler F. \& Waldburger M. 1994: Effects of pesticides on Chrysoperla carnea Steph. (Neuroptera, Chrysopidae) in the laboratory and semi-field. IOBC/WPRS Bull. 17(10): 55-69.

Bortolotti L., Porrini C., Micciarelli Sbrenna A. \& Sbrenna G. 2000: Ovicidal action of fenoxycarb on a predator, Chrysoperla carnea (Neuroptera: Chrysopidae). Appl. Entomol. Zool. 35: $265-270$

Bull D.L., Ridgway R.L., Buxkemper W.E., Schwarz M., Mc Govern T.P. \& SARMIENTo R. 1973: Effect of synthetic Juvenile Hormone Analogues on certain injurious and beneficial arthropods associated with cotton. J. Econ. Entomol. 66: 623-626.

CANARd M., SÉMÉRIA Y. \& New T.R. 1984: Biology of Chrysopidae. Dr W. Junk Publishers, The Hague, 294 pp.

Cappellozza L., Cappellozza S. \& Sbrenna G. 1995: Changes in the developmental programme of Bombyx mori caused by oral treatment with fenoxycarb during the last larval instar. Sericologia 35: 427-436.

Dedos S.G. \& Fugo H. 1999: Induction of dauer larvae by application of fenoxycarb early in the $5^{\text {th }}$ instar of the silkworm, Bombyx mori. J. Insect Physiol. 45: 767-775.

Dedos S.G., Fugo H. \& Kataoka H. 1998: A new cerebral factor stimulates $\mathrm{IP}_{3}$ levels in the prothoracic glands of Bombyx mori. Insect. Biochem. Molec. Biol. 28: 767-775.

Grenier S. \& GRenIER A.M. 1993: Fenoxycarb, a fairly new Insect Growth Regulator: a review of its effects on Insects. Ann. Appl. Biol. 122: 369-403.

Jones G., Hanzlik T., Hammock B.D., Schooley D.A., Miller C.A., Tsai L.W. \& BaKer F.C. 1990: The juvenile hormone titre during the penultimate and ultimate larval stadia of Trichoplusia ni. J. Insect Physiol. 36: 77-83.

Kamimura M. 1995: Effects of a Juvenile Hormone Analogue, fenoxycarb, on larval growth of silkworm, Bombyx mori (Lepidoptera: Bombicidae). Appl. Entomol. Zool. 30: 487-489.

NiImi S. \& SAKURAi S. 1997: Developmental changes in juvenile hormone acid titers in the hemolymph and in vitro juvenile hormone synthesis by corpora allata of the silkworm, Bombyx mori. J. Insect Physiol. 43: 875-884.

Nishout H.F. 1994: Insect Hormones. Princeton University Press, Princeton, New Jersey, 280 pp.
Plantevin G., Grenier S. \& Chavancy G. 1991: Effects of an insect growth regulator, fenoxycarb, on the postembryonic development of Bombyx mori (Lepidoptera, Bombicidae). $C$. R. Acad. Sci. (Ser. 3: Sciences de la Vie) 313: 513-519.

Romanchenko A.A., YakovchuK T.N. \& Popushoi I.S. 1987; Effects of Altosar and Altosid on pre-imaginal stages of the golden-eye (Chrysopa carnea Steph.) larvae. In Popushoi (ed.): Biological and Chemical Methods of Plant Protection. Amerind Publishing, New Delhi, pp. 27-30.

RumpF S. \& Penman D. 1993: Effects of the insect growth regulator fenoxycarb on two lacewing species in the laboratory and field. Proceedings of the 46th New Zealand Plant Protection Conference, Christchurch, New Zealand, 10-12 August 1993. New Zealand Plant Protection Society, pp. 97-100.

RumpF S., Storch V., Vogt H. \& Hassan S.A. 1992: Effects of juvenoids on larvae of Chrysoperla carnea Steph. (Chrysopidae). Acta Phytopath. Entomol. Hung. 27: 557-563.

RŮžIČKa Z., Sehnal F. \& Holman J. 1978: Effects of juvenoids on aphid predators. Acta Entomol. Bohemoslov. 75: 369-378.

Sehnal F. 1983: Juvenile Hormone Analogues. In Downer R.G.H. \& Laufer H. (eds): Endocrinology of Insects. Chapter XII: Hormones and Insect Control. Alan R. Liss, Inc., New York, pp. 657-672.

Tanaka S., Chang M.T., Denlinger D.L. \& Abdel-Aal Y.A.I. 1989: Developmental landmarks and the activity of juvenile hormone and juvenile hormone esterase during the last stadium and pupa of Lymantria dispar. J. Insect Physiol. 35: 897-905.

Triebskorn R., Köhler H.R., Zahn T., Vogt G., Ludwig M., RumpF S., Kratzmann M., Alberti G. \& Storch V. 1991: Invertebrate cells as targets for hazardous substances. $Z$. Angew. Zool. 78: 277-287.

VoGT H. 1992: Investigations on the side effects of insecticides and acaricides on Chrysoperla carnea Steph. (Neuroptera, Chrysopidae). Med. Fac. LandbWetensch. Rijksuniv. Gent 57: 559-567.

Vogt H. 1994: Effects of pesticides on Chrysoperla carnea Steph. (Neuroptera, Chrysopidae) in the field and comparison with laboratory and semi-field results. IOBC/WPRS Bull. 17(10): 71-82.

Received February 16, 2004; revised June 7, 2004; accepted December 3, 2004 